Received:

$27-I V-2020$

Accepted:

$5-\mathrm{V}-2020$

Published Online:

$6-\mathrm{V}-2020$

\section{COVID-19: Perspectives on the Pandemic and its Incidence in Dentistry}

\section{COVID-19: Perspectivas sobre la pandemia y su incidencia en odontología}

ABSTRACT: In December 2019, a novel coronavirus disease (COVID-19) presenting with pneumonia emerged in Wuhan, China. The ongoing spread of COVID-19 worldwide is creating enormous uncertainty. In particular, the dental profession is facing a major challenge. Due to the characteristics of dental settings, the risk of cross-infection is elevated between patients and dental staff. The present review aimed to briefly discuss the overview of the disease, including the basic science, epidemiology, symptoms, routes of transmission and several topics that the authors believe are binding and relevant to the dental practice. The guidelines adopted by governments and international organizations also address all dental associations to protect the health of the community and to contain the spread of COVID-19 infection until a vaccine or an effective/validated treatment becomes available.

KEYWORDS: Aerosols; COVID-19; Dentistry; Infection; Immune response; SARS-CoV-2; Vaccine.

RESUMEN: En diciembre del 2019, surgió una nueva enfermedad por coronavirus (COVID-19) que se presentó como una neumonía con etiología desconocida en Wuhan, China. La propagación continua de COVID-19 en todo el mundo está creando una enorme incertidumbre. En particular, la profesión dental se enfrenta a un gran desafío. Debido a las características de los consultorios dentales, el riesgo de infección cruzada es elevado entre los pacientes y el personal. La presente revisión tuvo como objetivo discutir brevemente la visión general de la enfermedad, incluyendo conceptos de ciencia básica, la epidemiología, vías de transmisión, síntomas y varios temas que los autores consideran vinculantes y relevantes para la práctica dental. Las directrices adoptadas por los gobiernos y las organizaciones internacionales también involucran a todas las asociaciones dentales para proteger la salud de la comunidad y contener la propagación de la infección por COVID-19 hasta que una vacuna 0 un tratamiento eficaz/validado esté disponible.

PALABRAS CLAVE: Aerosoles; COVID-19; Infección; Odontología; Respuesta inmune; SARS-CoV-2; Vacuna.

RAMÍREZ-MORA T., RETANA-LOBO C., REYES-CARMONA J., 2020: COVID-19: Perspectives on the Pandemic and its Incidence in Dentistry.ODOVTOS-Int. J. Dental Sc., 22-3 (September-December): 22-42. 


\section{INTRODUCTION}

In December 2019, clinical reports of patients with pneumonia of unknown etiology emerged in Wuhan City, China. Scientists identified severe acute respiratory syndrome coronavirus 2 (SARSCoV-2) as the etiologic agent, and the disease was subsequently named COVID-19 by the World Health Organization (WHO) (1). On January 30, 2020, the WHO Emergency Committee declared COVID-19 as a "public health emergency of international concern" (ESPII) (2), based on the impact that the virus could have in underdeveloped countries due to the rapid spread of the disease. Subsequently, on March 11 the disease was diagnosed in 114 territories worldwide and was recognized as a pandemic (3).

The COVID-19 pandemic has thrown the world into an economic and healthcare crisis. There are more than $3,573,864$ cases globally and more than 250.687 deaths (COVID-19 Update: 04/05/2020 https://coronavirus.jhu.edu/map.html) (Fig.1). The worldwide ongoing experience of COVID-19 is creating enormous uncertainty. Indeed, many countries have adopted unprecedented measures to curb the spread of the virus, such as large-scale use of isolation and quarantine, closing borders, imposing limits on public gatherings, and implementing nationwide lockdowns. Consequently, these measures had serious repercussions on the economic and social profile of the nations.

\section{SARS-COV-2 PHYLOGENETIC AND PATHOGENECY}

Coronaviruses (CoVs) is a large family of RNA viruses that possess a single-stranded positivesense RNA genome ranging from 26 to 32 kilobases in length (4).

As the largest known RNA viruses, CoVs are further divided into four genera: alphacoronavirus, beta-coronavirus, gamma-coronavirus and delta-coronavirus (5). To date, there have been six human coronaviruses (HCoVs) identified (6). As the published genome sequence for this novel coronavirus has a close resemblance to other beta-coronaviruses such as Severe acute respiratory syndrome (SARS)-CoV and Middle eastern respiratory syndrome (MERS)-CoV, the Coronavirus Study Group of the International Committee on Taxonomy of Viruses has given it the scientific name SARS-CoV-2 $(7,8)$.

Structurally, the SARS-CoV has a welldefined composition of 14 binding residues that directly interact with human angiotensin-converting enzyme 2 (ACE-2) (9). Of these amino acids, 8 have been conserved in SARS-CoV-2 (10).

SARS-CoV-2 is a spherical or pleomorphic enveloped particle containing single-stranded (positive-sense) RNA associated with a nucleoprotein within a capsid composed of matrix protein (11). The envelope bears club-shaped glycoprotein projections. Some coronaviruses also contain a hemagglutinin-esterase (HE) protein (Fig.2).

Phylogenetic and virus genome analyses have shown that coding regions of SARS-CoV-2 possess a similar genomic structure to batSLCoVZC45, bat-SL-CoVZXC21, and SARS-CoV (11). A complete genome evolutionary analysis of SARS-CoV-2 was performed and confirmed similar findings with $96.3 \%$ sequence similarity to the BatCo V RaTG 13 sequence (12). They concluded that SARS-CoV-2 likely originated from bats but rejected the possibility of this outbreak as a result of any recent recombination event (12). Hence, while the exotic animals are the definitive hosts, humans and domestic animals can be accidentally exposed to wild animals during their intentional or unintentional exposure to them (12).

Atomic-level understanding of SARSCoV-2 and its interaction with human cells has considerably clarified the pathogenesis of COVID-19 at the molecular level. Scientists have 
succeeded in recognizing the ACE-2 receptor as the site of attachment (13). ACE-2 was also the receptor for the SARS-COV responsible for the 2003-2004 outbreak (14). SARS-CoV-2 binds to ACE-2 by its spike, allowing the virus to enter and infect cells. Thus, the spike protein has to be primed by a protease called TMPRSS2 to complete this process (15-17). After the virus enters the host cell and uncoats, the genome is transcribed and then translated $(16,17)$. Coronavirus genome replication and transcription occurs at cytoplasmic membranes and involves a coordinated processes involving both continuous and discontinuous RNA synthesis (16-18).

A COVID-19 designed by Avesta Rasan (Appendix 1) illustrates how the disease affects our bodies. After 3 or 4 days of infection, macrophages release cytokines that cause vasodilation, causing symptoms to begin. Eventually, the fluid accumulates inside the alveoli, triggering collapse and decreased gas exchange. This may result in shortness of breath. If the inflammatory signaling increases, neutrophils are recruited to release reactive oxygen species (ROS) in an attempt to destroy infected cells. If the immune cells are destroyed, the alveolus collapse causes acute respiratory distress syndrome (ARDS). In this scenario, patients may require ventilators or life-support. Moreover, if the inflammation persists more severely, proteinrich fluid may enter the bloodstream triggering systemic inflammatory distress syndrome (SIRS), which could lead to septic shock and multi-organ failure (Fig.2).

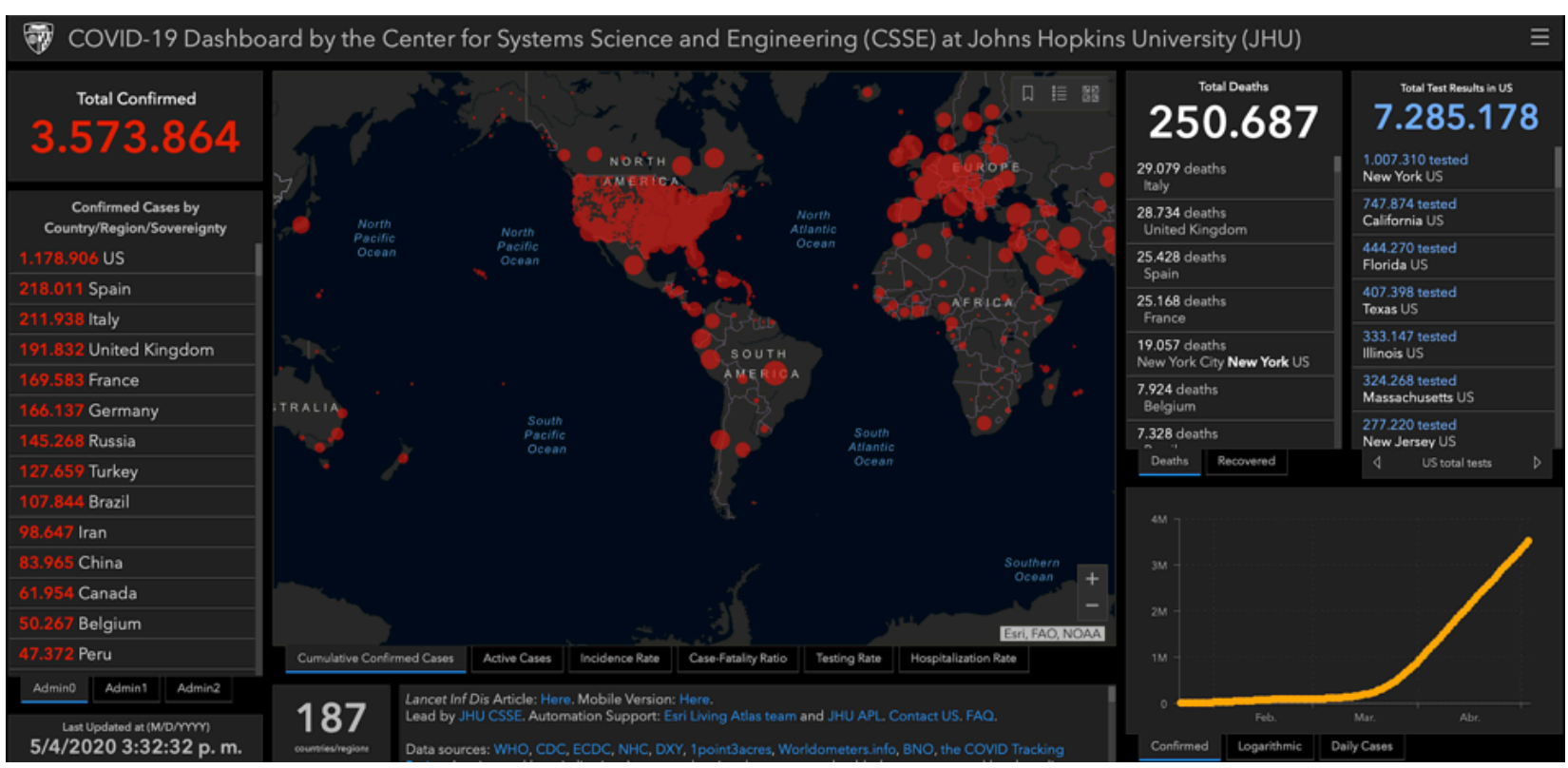

Figure 1. Screenshot of the COVID-19 dashboard of the Center for Systems Science and Engineering (CSSE) at Johns Hopkins University (JHU). Site accessed May 4, 2020 at: https://coronavirus.jhu.edu/map.html and is continually updated. 


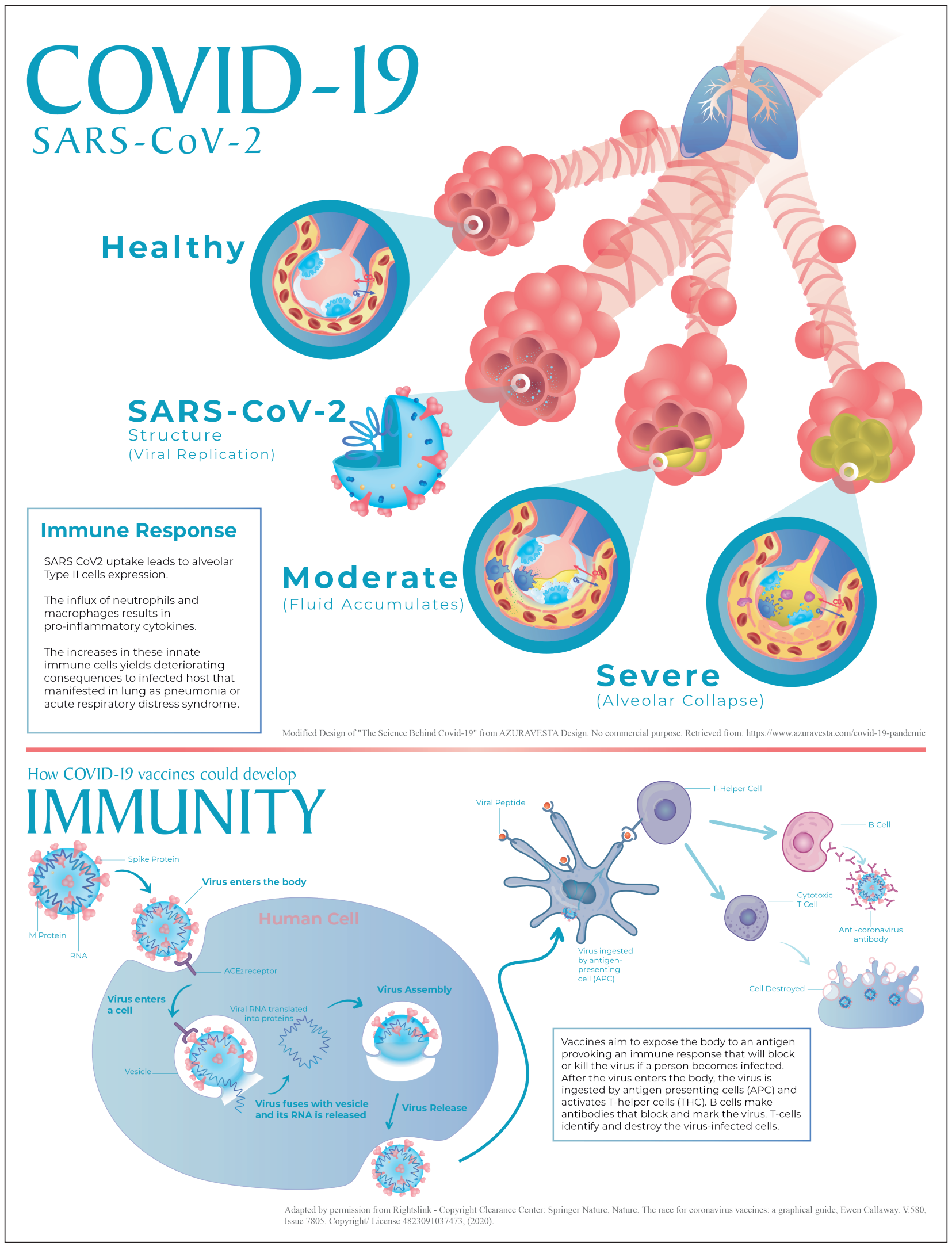

Figure 2. Immune response and How COVID-19 vaccines could develop immunity. 
VIRAL SHEDDING AND ROUTES OF TRANSMISSION OF COVID-19

SARS-CoV-2, the causative agent of COVID-19, spreads efficiently, with a basic reproductive number of 2.2 to 2.5 determined in Wuhan (19). Indeed, SARS and MERS did not cause the same level of devastation that COVID-19 has largely because they are not as easily transmitted. COVID-19, which can be spread by people without symptoms, spreads easily from person to person. Due to these characteristics, social distancing has become a crucial strategy to combat the spread.

The effectiveness of control measures depends on several epidemiological parameters, including the duration between infection and symptom onset in successive cases of a transmission chain (the serial interval) and the time between infection and onset of symptoms (the incubation period). According to the Centers for Disease Control and Prevention (CDC), the mean incubation period of SARS-CoV-2 is approximately 5.1 days (range 2-14 days). Moreover, a study suggested that viral shedding may begin 2 to 3 days before the appearance of the first symptoms. After symptom onset, viral loads decreased monotonically (20).

SARS-CoV-2 infections typically spread through respiratory droplets or contact (21). Major transmission routes include close or direct contact with infected secretions or large aerosol droplets (22). It is also important to consider that droplets of SARS-CoV-2 land on inanimate objects located near an infected individual and may subsequently be touched by other individuals (23). Thus, disinfection of objects and handwashing are essential for halting the spread of this disease.

Recently, there has been a growing concern over the possibility of the role of saliva and fecaloral transmission in COVID-19 (14,21-23). ACE-
2 receptor protein is highly concentrated in the epithelia of intestinal lumen and in salivary glands $(14,21)$. However when compared to MERS and SARS, patients with COVID-19 have reported less frequent gastrointestinal symptoms including diarrhea, nausea and vomiting (14).

The American Society of Microbiology stated an interesting and useful communication explaining the transmission dynamics of SARSCoV-2 in two steps (23):

\section{STEP 1: RELEASE}

When air passes over a layer of fluid in a person's respiratory tract, small particles, called droplets, are naturally created. Virus particles contained on the droplets are released into the environment when an infected person talks, coughs, sneezes or simply exhales.

\section{STEP 2: SPREAD}

The number, size of produced droplets, and the viral concentration all impact disease transmission. Droplets $>5-10 \mu \mathrm{m}$ in diameter are called respiratory droplets. They are larger, heavier and more likely to fall from the air before evaporating. Transmission from respiratory droplets occurs when a person touches a contaminated surface or gets caught directly in the spray zone of an infected patient (23). On the other hand, droplets $<5 \mu \mathrm{m}$ in diameter are called droplet nuclei or aerosols. These remain airborne for long periods of time and often float very long distances before evaporating (23). Transmission occurs when a person inhales droplet nucleus that are suspended in the air (23).

\section{CORONAVIRUS SYMPTOMS}

The CDC added 6 new symptoms on April 27,2020 . Fever, cough and shortness of breath are 
indications that a person might have the disease. In addition, if at least two of these symptoms are present, medical guidance is recommended:

- Fever

- Chills

- Repeated shaking with chills

- Muscle pain

- Headache

- Sore throat

- New loss of taste or smell

\section{IMPLICATIONS FOR DENTAL PRACTICE}

Due to the widespread transmission routes of SARS-CoV-2 and the characteristics of dental practice, there is an inherently high risk of crossinfection between dental professionals and patients. The nature of the dental procedures involves aerosol generation, a requires an operator in close proximity to the oropharyngeal region and the use of sharp instruments, increasing the probability of nosocomial infections. Therefore, to offer safe dental care, it is mandatory follow the recommended precautions from health organizations (WHO, CDC, ADA) in order to avoid dental staff potentially becoming infected and exposing the patients to the disease $(20,23,24)$.

\section{RISK OF CROSS-INFECTION IN DENTAL CLINICS}

One of the most important findings of the COVID-19 outbreak is the detection of SARS-CoV-2 in saliva (25). Sabino-Silva et al. suggested at least three different pathways to explain this relationship: 1) from the lower and upper respiratory tract that enters the oral cavity with the liquid droplets exchange, 2) from the virus present in the blood and access the mouth via crevicular fluid and 3) from the salivary gland epithelial cells (26).

Possible transmission routes for the SARS-CoV-2 include direct transmission (droplet inhalation), contact transmission (contact with mucous membranes) and dental settings invariably carry the risk of infection. For example, the generation of aerosols and droplets by dental devices such as high-speed handpiece or ultrasonic instruments, dental health care personnel (DHCP) in contact with human fluids, a waiting room with a number of persons in the dental office, became the perfect scenery for potential of coronavirus transmission (27).

\section{RECOMMENDATIONS FOR MINIMIZING THE RISK OF COVID-19 TRANSMISSION}

With data available from different reports and guidelines, we aimed to summarize specific and clear recommendations to be taken into account in order to prevent nosocomial infections.

\section{HAND HYGIENE}

DHCP should perform hand hygiene before and after interactions with all patients, contact with potentially infectious material and before putting on and after removing all personal protection equipment (PPE). The latter is particularly important to remove any pathogens that might reach skin during the removal process. Hand hygiene should be performed for all people that access the dental care facility (DCHP, patients) using 60-95\% alcohol or washing hands with soap and water for at least 20 seconds (28).

\section{STAY HOME IF SICK}

Before the dental care starts, DHCP should be self-monitoring for any respiratory symptoms (e.g. sore throat, fever, cough, shortness of breath) or other symptoms related to COVID-19 infection (e.g. anosmia, ageusia). It is strongly recommended that DHCP check their temperature twice a day. If any of these symptoms occur, DHCP should not report to work. It is also important to assess pre existing conditions (e.g. older age, immunocompromising 
conditions, pregnancy, chronic medical conditions) and avoid unnecessary exposure to potentially infected patients $(29,30)$.

\section{DENTAL OFFICE SET-UP}

Prepare dental clinics according to the regulations. Remove magazines, toys and any unnecessary objects from the waiting room. Clean and disinfect public areas frequently including waiting rooms, door handles, chairs and bathrooms. Print and place instructions for patients with the standard recommendations for respiratory hygiene and social distancing. Schedule appointments with enough time in between in order to avoid contact between patients in the waiting room and to disinfect the patient room properly, patient companions should wait outside clinic or car (30). Isolated and well-ventilated rooms or negatively pressured rooms are highly recommended for dental practice during the COVID-19 pandemic (23).

\section{SCREENING FOR COVID-19 AND TRIAGING DENTAL TREATMENTS}

Whenever possible, initial screening via telephone, video conference or text monitoring is strongly recommended. Remotely screen for COVID-19 through three main questions: 1) any exposure to a person with known or suspected COVID-19, 2) any recent travel history, 3) presence of any symptoms related to COVID-19 infection mentioned before. Positive responses to any of these questions should raise concern and reschedule the elective dental care, encourage the patients to be in quarantine and contact/report to the infection control department as soon as possible $(20,27)$ according to their country regulations. In Costa Rica people should call line 1322.

Asses the patient dental condition and determine the need to be seen in the dental settings. Services should be limited to emergency visits during the pandemic period and postpone elective procedures (29). Evaluate whether the problem/pain can be solved with medication through teledentistry. If the dental treatment can be delayed, give the patient careful instructions for home care and advise to contact the office if the condition worsens $(29,30)$.

In cases of emergency or urgent dental conditions such as trauma, severe dental pain from pulpal inflammation, pericoronitis, surgical post-operative osteitis, dental infections resulting in pain and swelling, orthodontic wires/piercing damaging the oral mucosa, etc. patients should be evaluated for COVID-19 infection symptoms to determine the clinical setting in which to treat them $(29,30)$.

Patients without symptoms related to COVID-19 and no history of exposure to the virus can be seen in dental settings with appropriate protocols and PPE. On the other hand, patients with active or suspected COVID-19 infection must be referred to an emergency department preferably in hospital settings, where appropriate transmissionbased precautions are available $(29,30)$.

As the pandemic progresses, patients infected with COVID-19 will recover and may need dental care. According to the Costa Rican Ministry of Health, a patient is considered fully recovered following a test-based strategy: asymptomatic cases with negative results in two consecutive tests separated from 24 hours (31). Thus, recovered patients (with diagnosis by the health authorities) could be treated following the authorities recommendations (29).

The urgency of a procedure is a decision based on clinical judgment and depends on the condition in each specific case. However, to have clarity on what is considered a real emergency situation and assess the risk of nosocomial infection, we strongly recommend following the ADA Interim Guidance for Management of Emergency and 
Urgent Dental Care which are based on the recommendations from the $\mathrm{WHO}$, the $\mathrm{CDC}$ and scientific literature and provide complete and clear guidelines through three algorithms (32).

\section{DENTAL TREATMENT}

Medical history: Upon patient arrival at the dental facility, patients should have a systematic and detailed medical history form, including COVID-19 screening. DHCP should check the patient's temperature using a non-contact forehead thermometer. Patients with fever $>38^{\circ} \mathrm{C}$ (except for those associated with an urgent dental infection) should be given a mask and be evaluated for signs/symptoms of acute respiratory infection. In suspected cases, advise patients to present in a hospital setting, preferably with dental consult available, in order to be tested. In addition, it is recommended to provide informed consent explaining the possible risks of receiving dental care during a pandemic period $(20,29)$.

Waiting room: Social distancing (2-meters) is mandatory, and if this is not possible, patients may wait outside or in their personal vehicle and wait to be called. DCHP should be aware or keep supplies for infection control protocols, like alcohol based hand rub (60-95\%), tissues and no touch receptacles for disposal at the facility entrance (30).

Infection control considerations: When emergency dental care is necessary, DHCP should adhere to standard practice (SP) as the minimum infection prevention practice applicable for all patient care including hand hygiene, use of PPE, respiratory hygiene protocols, safe injection practices, sharps safety, sterile instruments and devices, clean and disinfected environmental surfaces. If possible, DHCP should implement transmissionbased precautions: patient placement in isolated spaces, adequate room ventilation, respiratory protection (e.g.N95 masks) and postpone nonemergent procedures $(30,33)$.

PPE: Use the highest level of PPE available to protect skin and mucosa from potentially infected human fluids. Wear gloves, a gown, eye protection (googles with side protection or disposable/reusable face shield that covers front and sides of the face) and an N95/FFP2 or higher-level respirator, during the pandemic when caring for patients without COVID-19 $(29,34)$. If a respirator is not available, use a combination of a full-face shield and a surgical mask as the minimally accepted PPE, otherwise do not perform any emergency treatment and refer the patient (29). DHCP should follow the standard sequence of donning and doffing the PPE (Figure 3) as indicated by the CDC (35). Discard disposable PPE in a specific container for waste and clean and disinfect properly reusable PPE (29).

Preprocedural mouth rinse: Studies have shown that SARS-CoV-2 may be vulnerable to oxidation, suggesting the use of $0.5-1.5 \%$ hydrogen peroxide or $0.2 \%$ povidone iodine as a preprocedural mouthrinse that might reduce the load of virus in saliva $(20,29,30)$.

Aerosol-generating procedures (AGP): If possible, avoid aerosol generating procedures, such as the use of handpieces, air-water syringes and ultrasonic scalers. Minimally invasive or atraumatic restorative techniques (hand instruments) are encouraged. When AGP are necessary, DHCP should follow additional measures: use of PPE including N95/FFP2 or higher-level respirator, the use of four-handed technique, high-volume evacuation suction, handpieces with anti-retraction function and the use of a rubber dam (covering the nose) whenever possible to reduce the spread of microorganisms. The number of DHCPs present during the procedure should be limited to the minimum necessary to perform patient care and support, and visitors should not be present for the 
procedure (28). Additionally, if it is possible AGP should be scheduled as the last appointment of the day $(29,30,36)$.

Other treatment suggestions: Use disposable and single-use instruments and devices when possible to reduce the risk of cross-infection. Extraoral imaging is preferred when intraoral radiography is needed, sensors must be double-barriered to prevent cross contamination. In addition, resorbable sutures are preferred to avoid the need for a follow-up appointment. The use of disinfectants (hypochlorite, ethanol, hydrogen peroxide) in the handpiece and air-water syringe has been reported to reduce viral contaminants, even though their effect on coronaviruses is unknown $(20,29,30,36)$.

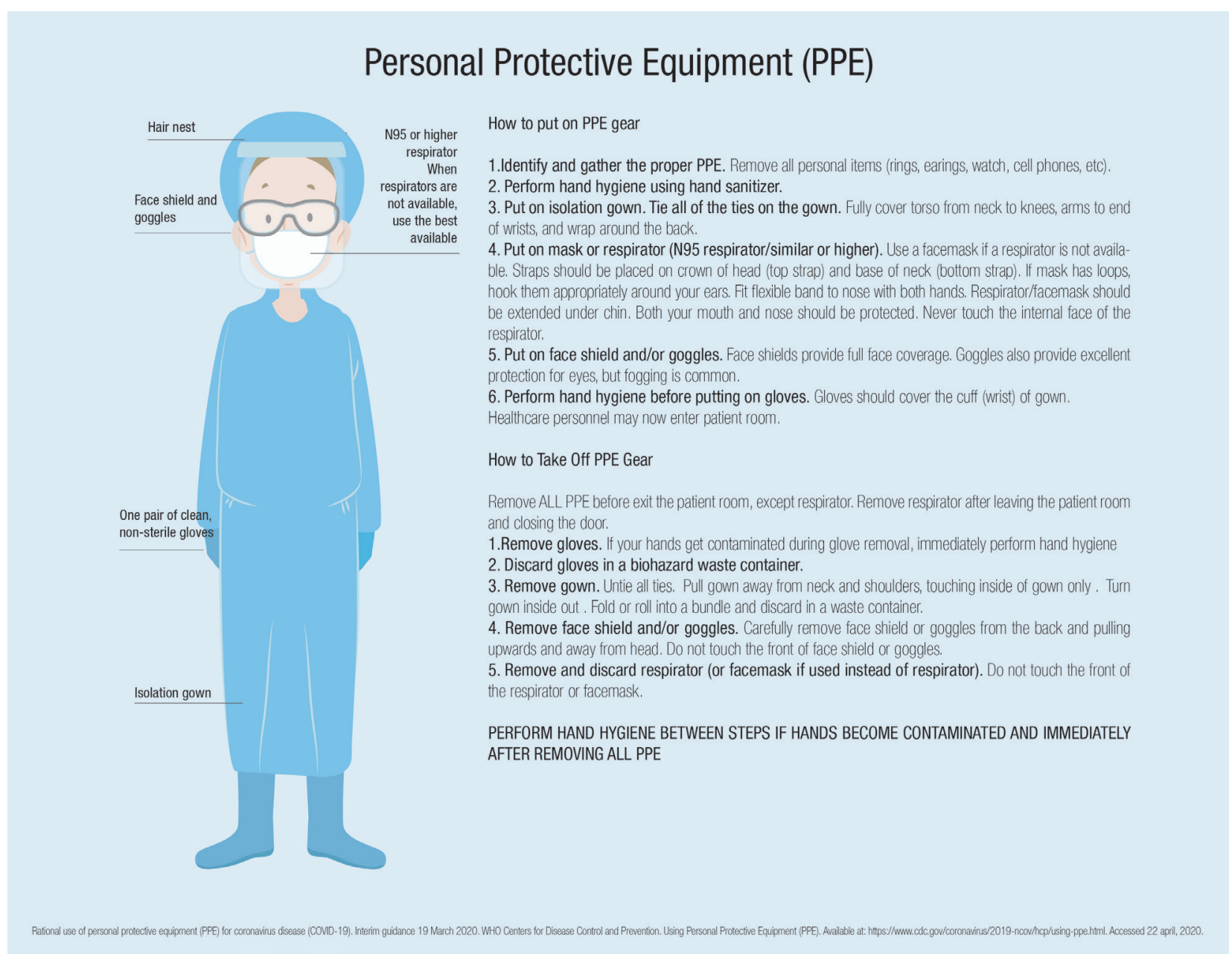

Figure 3. Personal Protective Equipment recommendations for daily clinical dental practice. 


\section{CONSIDERATIONS AFTER DENTAL CARE}

Between patients: Clean reusable PPE with soap and water. Handpieces should be cleaned to remove debris or any fluid followed by heat-sterilization after each patient. Cleaning and disinfection procedures of non-disposable equipment (e. g., dental x-ray, dental chair, light, etc.) and surfaces (door handles, chairs, desks, bathrooms, objects in possible contact with patients) should be performed, considering the appropriate contact times for each disinfect product (30).

When going home: DHCP should change scrubs to personal clothing before leaving the dental office. Upon arriving home, remove shoes and wash clothing separately and shower (30).

\section{POTENTIAL EXPOSURE GUIDANCE}

Although screening for possible infections may be performed appropriately, asymptomatic patients treated for dental emergencies can later be confirmed to have COVID-19. DCHP should establish a policy to keep track of a list of patients seen in the office and contact all patients 48 hours after their appointment to ask if they exhibit any signs or symptoms of COVID-19. Suspected cases should be referred for testing and request carefully to contact the clinic back to report results. If a previously treated patient is positive, the clinic must report the exposure to all patients treated after them and give detailed instructions for self-monitoring. If any symptoms consistent with COVID-19 appear, patients should ask for active monitoring from the public health authorities $(20,29,37)$.
PRESENCE OF SARS-COV-2 IN AEROSOLS AND SURFACES

It has been reported that SARS-CoV-2 can persist on inanimate surfaces reached by infected droplets. Transmission may occur with contact between infected surfaces and exposed mucosa or conjunctiva $(38,39)$. On the other hand, the presence of the SARS-CoV-2 as an aerosol or in air is not completely elucidated. Recently, New England Journal of Medicine reported the persistence of SARS-CoV-2 in aerosol particles for up to 3 hours (40). However, the experimental study was carried out under controlled laboratory conditions and may not reflect a clinical setting in which aerosol generating procedures are performed. In this sense, airborne transmission may be possible under specific conditions and settings in which aerosols are generated (38).

Human coronaviruses remain infectious on inanimate surfaces at room temperature, from hours to days according to the surface (metal-5 days, glass-4 days, plastic-up to 9 days, wood- 4 days, paper-5 days, etc.). Therefore, DCHP should disinfect all potentially contaminated surfaces with disinfectants that can effectively inactivate the virus (1-5 min). For example: 0,1\% sodium hypochlorite, $62-71 \%$ ethanol, $1 \%$ povidone-iodine and 0,5\% hydrogen peroxide (39). Added to this, hand hygiene consistently performed by all people at the facility may help to curb the spread.

\section{RECOMMENDATIONS FOR DENTAL SCHOOLS}

Dental education schools face significant challenges in the pandemic period due to the highly 
contagious nature of COVID-19 and the potential risk of cross infection inherent to a crowded health care facility. Meng et al. made recommendations for dental education during the outbreak:

Dental schools should move to online platforms and adopt online lectures, case studies and problem-based learning techniques to avoid unnecessary aggregation of professors and students. It is important to use programs or applications that make it possible for students to access the information at the moment they expect.

It is important to consider that students can be anxious because of the disease-associated fear and pressure regarding their academic situation. Dental education personnel should be prepared to advise and guide students to the right psychological support services at the university for those who may need it (23).

Regarding the improvements to control infection strategies when patient care returns, dental schools should be aware of the health office regulations and follow protocols strictly. They should maintain a minimum number of people at the facilities. When possible, building improvements/ modifications should be performed, according to the local government indications in order to avoid potential contamination.

At this time, there is not much information available because of the unexpected nature of the COVID-19 situation. Nevertheless, as research is conducted information will become available and we have to be receptive and willing to adapt to a new reality after COVID-19.

\section{DIAGNOSING COVID-19}

The COVID-19 pandemic underlines the essential role of diagnostics in the control of communicable diseases. The availability of accurate, fast, and reliable tools can enable the rapid implementation of control measures that limit the spread through case identification, isolation, and contact tracing (41).

In response to the high demand and need worldwide, a range of molecular techniques ranging from central laboratory testing to point-of-care tests are under development or already available for the diagnosis of COVID-19 $(42,43)$. These tests are mainly based on four different techniques: 1 ) reverse transcription polymerase chain reaction (RT-PCR), 2) loop-mediated isothermal amplification (LAMP), 3) lateral flow-hand-held single-use assays, and 4) enzyme-linked immunosorbent assay (ELISA) (44).

\section{CURRENT DIAGNOSTIC ASSAYS FOR COVID-19}

\section{REVERSE-TRANSCRIPTION POLYMERASE CHAIN REACTION (RT-PCR)}

The symptoms expressed by COVID-19 patients are nonspecific and can be related to other respiratory diseases (41). Therefore, molecular techniques are the gold standard of COVID-19 diagnostic testing and become the strategy recommended by the CDC to identify patients infected with SARS CoV-2 $(44,45)$.

PCR is a very common technique that has been widely used in research for more than 20 years to detect genetic information. A special version of this test is used, RT-PCR, in order to detect the SARS-CoV-2 RNA virus specifically. These tests are sensitive and reliable. The turnaround time for results varies with the availability of specialized equipment, ranging from 4 to 8 hours. Some RTPCR tests are developed as an 'all in one' kit, reducing laboratory handling "errors" and sample cross-contamination $(41,46,47)$.

RT-PCR detects whether the viral RNA is present in the patient sample. It does this by capturing and amplifying regions of the virus genetic material (spike protein, $\mathrm{N}$ protein or 
envelope) and uses fluorescent markers to detect the amount of viral RNA $(1,47,48)$. A positive result indicates that the virus currently infects the patient's sample. A negative result could represent different situations: 1) the person is not currently infected; 2) the virus is not present at the site where the sample was taken; 3 ) early or late stage of the infection during which viral replication is not detected (48).

\section{LOOP-MEDIATED ISOTHERMAL AMPLIFICATION (LAMP)}

LAMP technique includes an exponential amplification of specific nucleic acid sequences at a constant temperature; it has been widely used to detect virus-specific genes (ref). LAMP is newer compared to RT-PCR. However, its specificity and sensitivity are generally comparable to conventional PCR $(49,50)$.

The amplification of viral DNA and RNA using this technique can be detected by turbidity; this can be seen by the naked eye, allowing for easy diagnosis. The accuracy of the results can be improved by the introduction of fluorescent dyes. Thus, the test can detect whether or not the viral RNA is present in the sample $(44,49,50)$.

Isothermal amplification technique is simple to operate, easy to visualize, has less background signal, and does not require a thermocycler. In LAMP, a positive result means that the virus currently infects the patient, and a negative result can lead to the same situation as we mentioned for RT-PCR. When a negative result is obtained it is necessary to take new samples a few days later to reduce the false negative rate (51).

\section{LATERAL FLOW-COLLOIDAL GOLD IMMUNOCHROMATOGRAPHY}

Lateral flow techniques are commonly named "Antibody tests" as they are used to detect antibodies against a disease in a patient's blood, also it can be used to detect antigens $(42,44)$.

Commercial lateral flow assays use the same technology commonly used for pregnancy tests. The patient's sample (e.g., blood) is deposited on the membrane, and the proteins are drawn across the strip by capillary action. As the sample moves through the paper-like membrane, antibodies against SARS-CoV-2 that are present in the sample will attach to the antibody conjugates, capturing the antibodies and becoming visible as red and blue lines depending on the type of antibodies present $(\lg M$ or $\lg G)(44,50,52)$.

Since it is widely accepted that immunoglobulin M ( $(\mathrm{gM})$ provides the first line of defense during viral infections, testing of specific antibodies of SARS-CoV-2 in patient blood is a good option for rapid, simple, and highly sensitive diagnosis of COVID-19.

\section{ENZYME-LINKED IMMUNOSORBENT ASSAY (ELISA)}

ELISA is a commonly used analytical biochemistry test to detect antigens or antibodies. The technique uses a solid-phase enzyme immunoassay (EIA) to detect the presence of a ligand (commonly a protein) in a liquid sample using antibodies directed against the protein. This reaction produces a color change that can be measured by spectrophotometry $(47,53)$.

ELISAs can be performed for a large number of samples simultaneously, allowing for a cheap and time effective method. Detecting antibodies to SARS- CoV-2 could tell a clinician if a patient has been infected with COVID-19, either currently or in the past. It is important to remember that only when the adaptive immune response acts, antibodies can be detected. This occurs around 5 days after initial infection. This test may provide important information not only for diagnosis, but also for management and recovery from COVID-19 
and will also help health care personnel and sanitary authorities to evaluate how many people in the population have been infected, which is important for planning infection control in every country (48).

\section{EMERGING DIAGNOSTIC ASSAYS FOR COVID-19}

Recently the medical world has experienced tremendous advances in point-of-care diagnostics (POCD), which are essential for the rapid detection of analytes near the patient. These diagnostic devices are the result of continuous developments in biosensors, microfluidic, bioanalytical platforms, lab-on-a-chip technologies, etc. $(41,50)$.

As the spread of COVID-19 continues across the globe, fast, affordable test kits as diagnostic tools are becoming an urgent need to control the pandemic. In this sense, POCD based on microfluidic technology, which consists of a palm-size chip with micrometer-sized channels and reaction chambers have been developed (e. g., quantum dot barcode, smartphone dongle, paramagnetic bead, etc.). All of these technologies can be adapted for SARS-CoV-2 diagnosis and undoubtedly lab test companies soon develop them to help fight the spread of this emergent disease $(41,43,50)$.

Novel technologies, such as the Specific High Sensitivity Enzymatic Reporter unlocking (SHERLOCK ) platform enables the development of diagnostics that are better, faster and more affordable. They can diagnose virtually any disease rapidly, accurately, inexpensively and without the need for complex lab instruments or facilitating deployment in any setting. This platform is an evolution of Clustered Regularly Interspersed Short Palindromic Repeats (CRISPR), a powerful technique used to make precise edits in genetic code. Currently, the SHERLOCK ${ }^{\text {TM }}$ protocol for detecting SARS-CoV-2 has been released $(44,54,55)$.
Recently, researchers from different countries are investigating saliva as a potential diagnostic resource. SARS-CoV-2 was reportedly detected in initial saliva specimens from infected patients and has been validated as a source for detection. Compared to nasopharyngeal or oropharyngeal swabs, saliva showed an equal performance compared to the approved swab-based collection samples (56-58).

Saliva offers many benefits as a diagnostic fluid. It is easy to collect, store and can be a good alternative when nasopharyngeal specimen collection may be difficult or contraindicated to assess (26). It was recently revealed that this technique could be as accurate as or better than nasal swabs (Yale U Researchers). In April 2020, the US Food and Drug Administration (USFDA) authorized a saliva test for "emergency use" for diagnosing COVID-19. At Rutgers University, where the test was developed in collaboration with other groups, FDA announced their authorization. However, there is a lack of research on this test and further studies are required for validation. Saliva as a diagnostic tool could lead to better diagnosis and a better and effective strategy for prevention, especially for dental care professionals who perform AGP (58).

Dental education, research, and clinical practitioners should become more active and participate in scientific research projects to help manage the consequences of COVID-19 and other infectious diseases on oral health. Previous results have indicated that oral symptoms are significant in many patients with COVID-19. Loss of taste and smell are a common symptom in patients with COVID-19. Hence, dental health workers and researchers could play a more active role in diagnosis of the disease by deciphering the mechanisms of dry mouth and loss of taste and smell in patients with COVID-19 (59). 


\section{COVID-19 THERAPEUTIC MANAGEMENT}

Currently, there is no medicine or vaccine for COVID-19 that has been fully tested for safety and efficacy. Clinical management is based on what researchers have proposed, and some guidelines from Asia as the outbreak began in Wuhan City (the capital of Hubei province), China. COVID-19 treatment guidelines can vary in each country, but in general include different antiviral agents according to the latest guidelines from the National Health Commission (NHC) including Interferon, Lopinavir/ Ritonavir, Chloroquine Phosphate, Ribavirin, and Arbidol $(45,60)$. Angiotensin receptor blockers, such as losartan, are another option to treat COVID-19 $(61,62)$.

However, the main treatment protocol uses antivirals. China has relied on the use of the antiviral Favilavir, although no scientific evidence is available about its efficacy against COVID-19. It was approved in 2014 in Japan for influenza treatment. Favilavir does not have FDA approval (61). Another anti-viral drug, Remdesivir has shown efficacy against SARS-CoV and MERS-CoV in animals. China and the US FDA announced that clinical trials of Remdesivir have officially started to test its efficacy against COVID-19 $(45,62)$.

Chloroquine and hydroxychloroquine are widely used for prevention and treatment of malaria as well as certain inflammatory conditions (i.e. rheumatoid arthritis, lupus, and the blood disorder, porphyria cutanea tarda). In vitro results showed that chloroquine has a higher inhibition activity of SARS-CoV-2 compared to hydroxychloroquine. Some reports have also showed significant clinical improvement when used chloroquine and hydroxychloroquine, however, there is no clear evidence to support their use clinically $(47,63)$.

Protease inhibitors lopinavir/ritonavir have been used for the treatment of SARS-CoV and human immunodeficiency virus (HIV). A study examining the efficacy of these drugs against SARS-CoV2 showed no benefit compared to standard treatment. However, the WHO stated that using lopinavir/ritonavir with other drugs such as interferon- $\beta$, oseltamivir or ribavirin, could be beneficial in the treatment of COVID-19 patients (64). Darunavir (DRV), another anti-retroviral HIV-1 protease inhibitor, has been proposed as a treatment for COVID-19. So far, the results of two in vitro studies are contradictory; Chinese researchers showed that DRV significantly inhibited SARS- CoV-2 replication but in contrast, De Meyer et al. demonstrated that DRV has no activity against SARS-CoV-2 at clinically relevant concentrations. Again, there is insufficient data supporting the safety and efficacy of DRV for COVID-19 treatment (65).

Tocilizumab (TCZ) is a monoclonal antibody against interleukin-6 (IL-6). TCZ seems to be a good treatment option in COVID-19 patients with high levels of cytokine expression. A clinical trial in China used TCZ with promising results. Ninety five percent of the patients $(n=20)$ were cured and discharged from the hospital within two weeks (66).

Recently, Ivermectin an FDA-approved broadspectrum anti-parasitic agent has been shown to be effective against the SARS-CoV-2 virus in an in vitro study. The results demonstrate that this agent has anti-viral action against SARS CoV-2, raising the possibility of being a useful treatment for COVID-19. Further clinical trials are necessary to confirm in vitro results (67).

Convalescent plasma (CP) therapy, a treatment based on the concept of classic adaptive immunotherapy, has been used in the treatment of many human infectious diseases since the early 20th century (68). Different studies have reported that CP therapy has been successfully used during previous outbreaks (MERS-CoV, SARS-CoV, H1N1, and H5N1 avian flu) (69). Recently, the FDA issued a statement encouraging researchers to evaluate the use of blood plasma and purified 
immunoglobulins as possible treatments for COVID-19. In response to this call from FDA, the Clodomiro Picado Institute (ICP), of the University of Costa Rica, a research center devoted to the study of snake venoms and to the production of therapeutic antivenoms started a research focus on producing a $\mathrm{CP}$ treatment and antibody based immunotherapy. However, the potential clinical benefit and safety of convalescent blood products in COVID-19 remains uncertain and further studies are needed (70).

To our knowledge and based on the results published by Tobaiqy M. et al. (22), corticosteroids are the most widely used drug in studies investigating COVID-19 treatment, followed by anti-viral therapy, and hydrochloride. Drug discovery against SARSCoV-2 remains a challenging process as well as the development of an anti-virus vaccine. Therefore, understanding the biological properties of SARSCoV-2 and life cycle have become an essential priority $(62,63)$.

\section{THE EXPECTATION FOR THE DEVELOPMENT OF COVID-19 VACCINES}

Currently, more than 92 scientific teams in universities and companies are developing different strategies against SARS-CoV-2. Recently was published in Nature the different technologies that the researchers are trialing in the race for COVID-19 vaccine (71). Some groups are already injecting formulations into volunteers in safety clinical trials, others in animals.

Vaccines aim to expose the body to an antigen provoking an immune response that will block or kill the virus if a person becomes infected (Fig. 2). There are several types of vaccines against coronavirus being tested, including Virus vaccines (Weakened or Inactivated virus), Nucleic-Acid
Vaccines, Viral-Vector Vaccines and Protein-based vaccines (71).

Traditional vaccine approaches rely on growing the virus, in a laboratory, in greater volumes, and then inactivating it, or by culturing viruses over time to gradually weaken them until they are safe. However, these methods take a long time before they are ready for clinical use. It seems that the most relevant approaches are focusing on the genetic code of the spike protein on the surface of the virus called the receptor-binding domain, and use that with adjuvants like immune-stimulating molecules, as a vaccine. When this type of vaccine is injected into the body, muscle cells naturally "amplify" it by producing copies of the spike protein which the immune system detects as a threat (71). This trains the body's immune system to defend against SARS-CoV-2 through being able to recognize the spike protein when a person becomes infected. However, the scientific teams leading the different approaches do not estimate when this vaccine would be available for clinical use.

\section{CONCLUSION}

In conclusion, dentists have a duty to protect the community, content the expansion of the disease and maintain high standards of care and infection control. Therefore, it is important to be alert, analyze the different variables to perform ethical and clinical decisions, educate our patients and implement each of the recommendations issued by both national and international organizations. As leaders in the field of oral health and as a union we must remain strong, determined, prudent and willing to change in order to guarantee the well-being of our patients. Finally, this is the moment for all of us to rise to the challenge of collaborative leadership and work together to find pathways to emerge from this crisis with a global dental professional reset. 


\section{REFERENCES}

1. World Health Organization, WHO DirectorGeneral's Remarks at the Media Briefing on 2019-nCoV on 11 February 2020; 2020 [cited 2020 Feb 10]. Available from: https://www. who.int/dg/speeches/detail/who-directorgeneral-s-remarks-at-the-media-briefing-on2019-ncov-on-11-february-2020

2. Organización Mundial de la Salud. Declaración sobre la segunda reunión del Comité de Emergencias del Reglamento Sanitario Internacional (2005) acerca del brote del nuevo coronavirus (2019-nCoV); [cited 2020 Feb 1]. Available from: https:/www.who.int/ es/news-room/detail/30-01-2020-statementon-the-second-meeting-of-the-internationalhealth-regulations-(2005)-emergencycommittee-regarding-the-outbreak-of-novelcoronavirus-(2019-ncov)

3. Organización Mundial de la Salud. Alocución de apertura del Director General de la OMS en la rueda de prensa sobre la COVID-19 celebrada el 11 de marzo de 2020; [cited 2020 Mar 11]. Available from: https://www. who.int/es/dg/speeches/detail/who-directorgeneral-s-opening-remarks-at-the-mediabriefing-on-covid-19---11-march-2020

4. Su S., Wong G., Shi W., Liu J., LaiA.C.K., Zhou J., Liu W., Bi Y., Gao G. F. Epidemiology, genetic recombination, and pathogenesis of coronaviruses. Trends Microbiol. 2016; 24 (6): 490-502.

5. Li F. Structure, function, and evolution of coronavirus spike proteins. Annu Rev Virol. 2016; 3 (1): 237-61.

6. Wu A.., Peng Y., Huang B., Ding X., Wang X., Niu P., Meng J., Zhu Z., Zhang Z., Wang J., Sheng J., Quan L., Xia Z., Tan W., Cheng G., Jiang T. Genome composition and divergence of the novel coronavirus (2019-nCoV) originating in China. Cell Host Microbe. 2020; 27 (3): 325-28.
7. Zhu N., Zhang D., Wang W., Li X., Yang B., Song J., Zhao X., Huang B., Shi W., Lu R., Niu P., Zhan F., Ma X., Wang D., Xu W., Wu G., Gao G. F., Tan W.; China Novel Coronavirus Investigating and Research Team. A novel coronavirus from patients with pneumonia in China, 2019. N Engl J Med 2020; 382 (8): 727-33.

8. Coronaviridae Study Group of the International Committee on Taxonomy of Viruses. The species severe acute respiratory syndromerelated coronavirus: classifying 2019-nCoV and naming it SARS-CoV-2. Nat Microbiol. 2020; 5 (4): 536-44.

9. Sohrabi C., Alsafi Z., O'Neill N., Khan M., Kerwan A., Al-Jabir A., Iosifidis C., Agha R.. World Health Organization declares global emergency: A review of the 2019 novel coronavirus (COVID-19). Int J Surg. 2020; 76: 71-76.

10. Fehr A. R., Perlman S. Coronaviruses: an overview of theirreplication and pathogenesis. Methods Mol Biol. 2015; 1282: 1-23.

11. Mousavizadeh L., Ghasemi S. Genotype and phenotype of COVID-19: Their roles in pathogenesis [published online ahead of print, 2020 Mar 31]. J Microbiol Immunol Infect. 2020; S1684-1182 (20) 30082-7.

12. Lu R., Zhao X., Li J., Niu P., Yang B., Wu H., Wang W., Song H., Huang B., Zhu N., Bi Y., Ma X1, Zhan F., Wang L., Hu T., Zhou H., Hu Z., Zhou W., Zhao L., Chen J., Meng Y., Wang J., Lin Y., Yuan J., Xie Z., Ma J., Liu W. J., Wang D., Xu W., Holmes E. C., Gao G. F., Wu G., Chen W., Shi W., Tan W. Genomic characterization and epidemiology of 2019 novel corona virus: implications for virus origins and receptor binding. Lancet 2020; 395 (10224): 565-74.

13. Paraskevis O., Kostaki E. G., Magiorkinis G., Panayiotakopoulos G., Sourvinos G., Tsiodras S.. Full-genome evolutionary analysis of the novel corona virus (2019- 
$\mathrm{nCoV}$ ) rejects the hypothesis of emergence as a result of a recent recombination event. lnfect Genet Evol. 2020; 79: 104212.

14. SahuK.K.,MishraA.K.,LalA.COVID-2019: update on epidemiology, disease spread and management. Monaldi Arch Chest Dis. 2020; 90 (1). doi:10.4081/monaldi.2020.1292

15. Wan Y., Shang J., Graham R., Baric R. S., Li F. Receptor recognition by novel coronavirus from Wuhan: an analysis based on decadelong structural studies of SARS. J Virol 2020; 94 (7): pii: e00127-20.

16. Hoffmann M., Kleine-Weber H., Schroeder S., Krüger N., Herrler T., Erichsen S., Schiergens T. S., Herrler G., Wu N.H., Nitsche A., Müller M. A., Drosten C., Pöhlmann S. SARS-CoV-2 cell entry depends on ACE2 and TMPRSS2 and is blocked by a clinically proven protease inhibitor. Cell. 2020; 181 (2): 271-80.e8.

17. Guo Y-R, Cao Q-D, Hong Z-S, Tan Y-Y, Chen S-D, Jin H-J, Tan KS, Wang DY, Yan Y. The origin, transmission and clinical therapies on coronavirus disease 2019 (COVID-19) outbreak an update on the status. Mil Med Res 2020; 7 (1): 1e10.

18. Li Q., Guan X., Wu P., Wang X., Zhou L., Tong Y., Ren R., Leung K. S. M., Lau E. H. Y., Wong J. Y., Xing X., Xiang N., Wu Y., Li C., Chen Q., Li D., Liu T., Zhao J., Liu M., Tu W., Chen C., Jin L., Yang R., Wang Q., Zhou S., Wang R., Liu H., Luo Y., Liu Y., Shao G., Li H., Tao Z., Yang Y., Deng Z., Liu B., Ma Z., Zhang Y., Shi G., Lam T. T. Y., Wu J. T., Gao G. F. L., Cowling B. J., Yang B., Leung G. M., Feng Z. Early transmission dynamics in Wuhan, China, of novel coronavirus-infected pneumonia. N Engl J Med. 2020; 382 (13): 1199-1207.

19. Zou L., Ruan F., Huang M., Liang L., Huang H., Hong Z., Yu J., Kang M., Song Y., Xia
J., Guo Q., Song T., He J., Yen H. L., Peiris M., Wu J. SARS-CoV-2 viral load in upper respiratory specimens of infected patients. N Engl J Med. 2020; 382 (12): 1177-79.

20. Ather A., Patel B., Ruparel N. B., Diogenes A., Hargreaves K. M. Coronavirus disease 19 (COVID-19): implications for clinical Dental Care. J Endod. 2020; 46 (5): 584-95.

21. Lui, S. et al. World Health Organization declares global emergency: A review of the 2019 novel coronavirus (COVID-19). Int J Surg. 2020; 76: 71-76.

22. Hagen, A. COVID-19 transmission dynamics. American Society for Microbiology; 2020 [cited 2020 Apr 23]. Available from: https:// stage.asm.org/Articles/2020/April/COVID19-Transmission-Dynamics

23. Meng L., Hua F., Bian Z. Coronavirus disease 2019 (COVID-19): emerging and future challenges for dental and oral medicine. $\mathrm{J}$ Dent Res. 2020; 99 (5): 481-87.

24. Spagnuolo G., De Vito D., Rengo S., Tatullo M. COVID-19 outbreak: an overview on dentistry. Int J Environ Res Public Health. 2020; 17 (6): 2094.

25. To K. K., Tsang O. T., Chik-Yan Yip C., Chan K. H., Wu T. C., Chan J. M. C., Leung W. S., Chik T. S., Choi C. Y., Kandamby D. H., Lung D. C., Tam A. R., Poon R. W., Fung A. Y., Hung I. F., Cheng V. C., Chan J. F., Yuen K. Y. Consistent detection of 2019 novel coronavirus in saliva. Clin Infect Dis. 2020; ciaa149. doi: 10.1093/cid/ciaa149

26. Sabino-Silva R., Jardim A. C. G., Siqueira W. L. Coronavirus COVID-19 impacts to dentistry and potential salivary diagnosis. Clin Oral Investig. 2020; 24 (4): 1619-21.

27. Peng X., Xu X., Li Y., Cheng L., Zhou X., Ren B. Transmission routes of 2019-nCoV and controls in dental practice. Int J Oral Sci. 2020; 12 (1): 9. 
28. Centers for Disease Control and Prevention. Interim infection prevention and control recommendations for patients with suspected or confirmed coronavirus disease 2019 (COVID-19) in healthcare settings; 2020 [cited 2020 April 24]. Available at: https:// www.cdc.gov/coronavirus/2019-ncov/ infection-control/control-recommendations. html

29. Centers for Disease Control and Prevention. Interim infection prevention and control guidance for dental settings during the COVID-19 response. 2020 [cited 2020 Apr 23]. Available from: https://www.cdc.gov/coronavirus/2019ncov/hcp/dental-settings.html

30. American Dental Association. ADA Interim guidance for minimizing risk of COVID-19 transmission; 2020 [cited 2020 April 20]. Available at: https://www.ada.org/ /media/ CPS/Files/COVID/ADA_COVID_Int_ Guidance_Treat Pts

31. Ministerio de Salud de Costa Rica, Caja Costarricense de Seguro Social, INCIENSA, OPS. Lineamientos Nacionales para la Vigilancia de la enfermedad COVID-19 Costa Rica Versión $\mathrm{N} \circ$ 7. 2020 [cited 2020 Apr 23]. Available from: https:/www.ministeriodesalud.go.cr/ sobre_ministerio/prensa/docs/version_7 lineamientos_nacionales_vigilancia_ infeccion_coronavirus_11032020.pdf.

32. American Dental Association. ADA interim guidance for management of emergency and urgent dental care; 2020 [ cited 2020 Apr 20]. Available from: https://www.ada.org/ /media/ CPS/Files/COVID/ADA_Int_Guidance Mgmt_Emerg-Urg_Dental_COVID19.pdf

33. Centers for Disease Control and Prevention. Summary of infection prevention practices in dental settings basic expectations; 2016 [cited 2020 Apr 25]. Available from: https:// www.cdc.gov/oralhealth/infectioncontrol/ pdf/safe-care2.pdf

34. World Health Organization (WHO). Rational use of personal protective equipment for coronavirus disease (COVID-19) and considerations during severe shortages; 2020 [cited 2020 Apr 26]. Available from: https:// www.who.int/publications-detail/rationaluse-of-personal-protective-equipmentfor-coronavirus-disease-(covid-19)-andconsiderations-during-severe-shortages.

35. Centre for Disease Control and Prevention. Use personal protective equipment (PPE) when caring for patients with confirmed or suspected COVID-19; 2020 [cited 2020 Apr 23]. Available from: https://www.cdc.gov/ coronavirus/2019-ncov/downloads/A_FS_ HCP_COVID19_PPE.pdf

36. Alharbi A., Alharbi S., Alqaidi S. Guidelines for dental care provision during the COVID-19 pandemic. Saudi Dent J. doi: 10.1016/j. sdentj.2020.04.001

37. Center for Disease Control and Prevention. Interim U.S. guidance for risk assessment and public health management of healthcare personnel with potential exposure in a healthcare setting to patients with coronavirus disease 2019 (COVID-19); 2020 [cited 2020 Apr 24]. Available from: https://www.cdc. gov/coronavirus/2019-ncov/hcp/guidancerisk-assesment-hcp.html

38. World Health Organization. Modes of transmission of virus causing COVID-19: implicationsforIPCprecautionrecommendations; 2020 [cited 2020 Apr 25]. Available from: https:// www.who.int/news-room/commentaries/detail/ modes-of-transmission-of-virus-causingcovid-19-implications-for-ipc-precautionrecommendations

39. Kampf G., Todt D., Pfaender S., Steinmann E. Persistence of coronaviruses on inanimate surfaces and their inactivation with biocidal agents. J Hosp Infect. 2020;104 (3): 246-51.

40. van Doremalen N., Bushmaker T., Morris D. H., Holbrook M. G., Gamble A., Williamson B. N., Tamin A., Harcourt J. L., Thornburg N. J., Gerber S. I., Lloyd-Smith J. O., de Wit E., Munster V. J. Aerosol and surface stability of 
SARS-CoV-2 as compared with SARS-CoV-1. N Engl J Med. 2020; 382 (16): 1564-67.

41. Udugama B., Kadhiresan P., Kozlowski H. N., Malekjahani A., Osborne M., Li V. Y. C., Chen H., Mubareka S., Gubbay J. B., Chan W. C. W. Diagnosing COVID-19: the disease and tools for detection [published online ahead of print, 2020 Mar 30]. ACS Nano. 2020; 14 (4): 3822-35.

42. Vashist S. K. Point-of-care diagnostics: Recent advances and trends. Biosensors (Basel). 2017; 17 (4): E62.

43. Cheng M. P., Papenburg J., Desjardins M., Kanjilal S., Quach C., Libman M., Dittrich S., Yansouni C. P. Diagnostic testing for severe acute respiratory syndrome-related coronavirus-2. Ann Intern Med. 2020. doi: 10.7326/M20-1301

44. Song J., Wang G., Zhang W., Zhang Y., Li W., Zhou Z.; People's Liberation Army Professional Committee of Critical Care Medicine, Chinese Society on Thrombosis and Haemostasis. Chinese expert consensus on diagnosis and treatment of coagulation dysfunction in. Mil Med Res. 2020; 7 (1): 19.

45. McCreary E. K., Pogue J. M. Coronavirus disease 2019 treatment: a review of early and emerging options. Open Forum Infect Dis. 2020; 7 (4): ofaa105.

46. Xiao A. T., Tong Y. X., Gao C., Zhu L., Zhang Y. J., Zhang S. Dynamic profile of RTPCR findings from 301 COVID-19 patients in Wuhan, China: a descriptive study. J Clin Virol. 2020:104346. doi: 10.1016/j. jcv.2020.104346

47. Zhai P., Ding Y., Wu X., Long J., Zhong Y., Li Y. The epidemiology, diagnosis and treatment of COVID-19. Int J Antimicrob Agents. 2020: 105955.

48. Green K., Winter A., Dickinson R., Graziadio S., Wolff R., Mallett S., Allen A. J. What tests could potentially be used for the screening, diagnosis and monitoring of COVID-19 and what are their advantages and disadvantages? Centre for Evidence-Based Medicine. 2020. Available from: https://www.cebm. net/covid-19/what-tests-could-potentiallybe-used-for-the-screening-diagnosis-andmonitoring-of-covid-19-and-what-are-theiradvantages-and-disadvantages/

49. Baek Y. H., Um J., Antigua K. J. C., Park J. H., Kim Y., Oh S., Kim Y. I., Choi W. S., Kim S. G., Jeong J. H., Chin B. S., Nicolas H. D. G., Ahn J. Y., Shin K. S., Choi Y. K., Park J. S., Song M. S. Development of a reverse transcriptionloop-mediated isothermal amplification as a rapid early-detection method for novel SARS-CoV-2. Emerg Microbes Infect. 2020; 1-31. doi: 10.1080/22221751.2020.1756698

50. Nguyen T., Duong Bang D., Wolff A. 2019 novel coronavirus disease (COVID-19): paving the road for rapid detection and pointof-care diagnostics. Micromachines (Basel). 2020; 11 (3): 306.

51. Park G. S., Ku K., Baek S. H., Kim S. J., Kim S. I., Kim B. T., Maeng J. S.Development of reverse transcription loop-mediated isothermal amplification assays targeting SARS-CoV-2. J Mol Diagn. 2020; S1525-1578 (20) 30090-8.

52. Yan C., Cui J., Huang L., Du B., Chen L., Xue G., Li S., Zhang W., Zhao L., Sun Y., Yao H., Li N., Zhao H., Feng Y., Liu S., Zhang Q., Liu D., Yuan J. Rapid and visual detection of 2019 novel coronavirus (SARS-CoV-2) by a reverse transcription loop-mediated isothermal amplification assay. Clin Microbiol Infect. 2020;S1198-743X(20)30186-5. doi: 10.1016/j.cmi.2020.04.001

53. Li X., Geng M., Peng Y., Meng L., Lu S. Molecular immune pathogenesis and diagnosis of COVID-19. J Pharm Anal. 2020. doi: 10.1016/j.jpha.2020.03.001 
54. Sheridan C. Fast, portable tests come online to curb coronavirus pandemic. Nat Biotechnol. 2020. doi: 10.1038/d41587-020-00010-2

55. Liu R., Fu A., Deng Z., Li Y., Liu T. Promising methods for detection of novel coronavirus SAR-SCoV-2. View. 2020 Mar; 1 (1).

56. Kakodkar P., Kaka N., Baig M. N. A comprehensive literature review on the clinical presentation, and management of the pandemic coronavirus disease 2019 history of the outbreak. Cureus. 2020; 12 (4): e7560.

57. Sri Santosh T., Parmar R., Anand H., Srikanth K., Saritha M. A review of salivary diagnostics and its potential implication in detection of Covid-19. Cureus. 2020; 12 (4): e7708.

58. Azzi L., Carcano G., Gianfagna F., Grossi P., Gasperina D. D., Genoni A., Fasano M., Sessa F., Tettamanti L., Carinci F., Maurino V., Rossi A., Tagliabue A., Baj A. Saliva is a reliable tool to detect SARS-CoV-2. J Infect. 2020: S0163-4453 (20) 30213-9.

59. Ren Y. F., Rasubala L., Malmstrom H., Eliav E. Dental care and oral health under the clouds of COVID-19. JDR Clin Transl Res. 2020. 238008442092438. doi: $10.1177 / 2380084420924385$

60. Yousefifard M., Zali A., Ali K. M., Madani Neishaboori A., Zarghi A., Hosseini M., Safari S. Antiviral therapy in management of COVID-19: a systematic review on Current evidence. Arch Acad Emerg Med. 2020; 8 (1): e45.

61. El-Aziz T. M. A., Stockand J. D. Recent progress and challenges in drug development against COVID-19 coronavirus (SARS-CoV-2) - an update on the status. Infect Genet Evol. 2020. 104327.

62. Tobaiqy M., Qashqary M., Al-Dahery S., Mujallad A, Hershan AA, Kamal MA, Helmi N. Therapeutic management of COVID-19 patients: a systematic review. Infect Prev Pract. 2020:100061.
63. Zhang J., Xie B., Hashimoto K. Current status of potential therapeutic candidates for the COVID-19 crisis. Brain Behav Immun. 2020;S0889-1591 (20) 30589-4.

64. Cao B., Wang Y., Wen D., Liu W., Wang J., Fan G., Ruan L., Song B., Cai Y., Wei M., Li X., Xia J., Chen N., Xiang J., Yu T., Bai T., Xie X., Zhang L., Li C., Yuan Y., Chen H., Li H., Huang H., Tu S., Gong F., Liu Y., Wei Y., Dong C., Zhou F., Gu X., Xu J., Liu Z., Zhang Y., Li H., Shang L., Wang K., Li K., Zhou X., Dong X., Qu Z., Lu S., Hu X., Ruan S., Luo S., Wu J., Peng L., Cheng F., Pan L., Zou J., Jia C., Wang J., Liu X., Wang S., Wu X., Ge Q., He J., Zhan H., Qiu F., Guo L., Huang C., Jaki T., Hayden F. G.1, Horby P. W., Zhang D., Wang C. A trial of lopinavir-ritonavir in adults hospitalized with Severe Covid-19 [published online ahead of print, 2020 Mar 18]. N Engl J Med. 2020; NEJMoa2001282.

65. Meyer S. De, Bojkova D., Cinati J., Damme E. Van, Buyck C., Van Loock M., Woodfall B., Ciesek S. Lack of antiviral activity of darunavir against SARS-CoV-2. medRxiv. doi: 2020.04.03.20052548

66. Luo P., Liu Y., Qiu L., Liu X., Liu D., Li J. Tocilizumab treatment in COVID-19: a single center experience. J Med Virol. 2020. 32253759

67. Caly L., Druce J. D., Catton M. G., Jans D. A., Wagstaff K. M. The FDA-approved drug ivermectin inhibits the replication of SARSCoV-2 in vitro [published online ahead of print, 2020 Apr 3]. Antiviral Res. 2020; 178: 104787.

68. Marano G., Vaglio S., Pupella S., Facco G., Catalano L., Liumbruno G. M., Grazzini G. Convalescent plasma: new evidence for an old therapeutic tool? Blood Transfus. 2016; 14 (2): 152-57.

69. Ahn J. Y., Sohn Y., Lee S. H., Cho Y., Hyun J. H., Baek Y. J., Jeong S. J., Kim J. H., Ku N. 
S., Yeom J. S., Roh J., Ahn M. Y., Chin B. S., Kim Y. S., Lee H., Yong D., Kim H. O., Kim S., Choi J. Y. Use of convalescent plasma therapy in two COVID-19 patients with acute respiratory distress syndrome in Korea. J Korean Med Sci. 2020; 35 (14): e149.

70. Moreno E., Lomonte B., Gutiérrez J. M. Computational biology in Costa Rica: the role of a small country in the global context of bioinformatics. PLoS Comput Biol. 2008; 4 (3): e1000040.

71. Chart Sources: Nature Analysis Based On Who Covid-19 Vaccine Landscape/Milken Institute Covid-19 Treatment And Vaccine Tracker/T. Thanh Le Et Al. Nature Rev. Drug. Disc. Http://Doi.Org/Ggrnbr (2020)/F. Amanat \& F. Krammer Immunity 52, 583-589 (2020)/W. Shang Et Al. Npj Vaccines 5, 18 (2020).

Tatiana Ramírez-Mora DDS, MSD, PhD1; Cristina Retana-Lobo DDS, MSD; Jessie Reyes-Carmona DDS, MSD, PhD'1

1. Section of Endodontics, Restorative Sciences Department, Faculty of Dentistry, University of Costa Rica. LICIFO-Laboratory of Research, Costa Rica.

Correspondence to: Jessie Reyes-Carmona - jessie.reyes@ucr.ac.cr
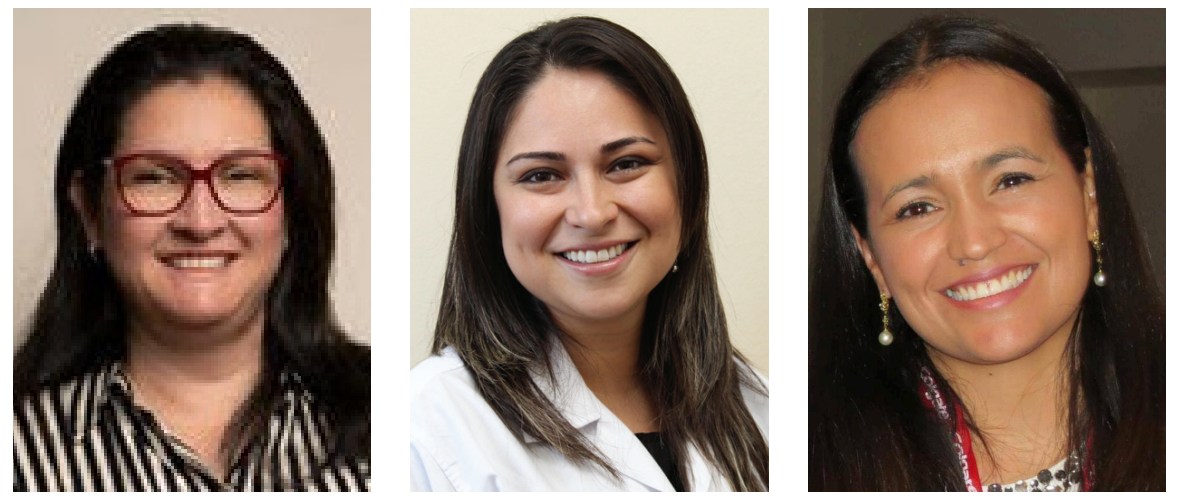

Attribution (BY-NC) - (BY) You must give appropriate credit, provide a link to the license, and indicate if changes were made. You may do so in any reasonable manner, but not in any way that suggest the licensor endorses you or your use. (NC) You may not use the material for commercial purposes. 